\title{
The Development of Extended Reality in Education: Inspiration from the Research Literature
}

\author{
Xingrong Guo ${ }^{1, *} \mathbb{D}$, Yiming Guo ${ }^{2, *}$ and Yunqin Liu $^{3}$ \\ 1 College of Foreign Languages, Shanghai Maritime University, Shanghai 201306, China \\ 2 School of Economics and Management, Shanghai Maritime University, Shanghai 201306, China \\ 3 Tourism Management Department, Hunan Vocational College of Commerce, Changsha 410205, China; \\ liuyunqin@hnswxy.com \\ * Correspondence: xmguo@shmtu.edu.cn (X.G.); ymguo@shmtu.edu.cn (Y.G.)
}

Citation: Guo, X.; Guo, Y.; Liu, Y. The Development of Extended Reality in Education: Inspiration from the Research Literature. Sustainability 2021, 13, 13776. https://doi.org/ $10.3390 /$ su132413776

Academic Editor: Eila Jeronen

Received: 11 November 2021

Accepted: 9 December 2021

Published: 14 December 2021

Publisher's Note: MDPI stays neutral with regard to jurisdictional claims in published maps and institutional affiliations.

Copyright: (c) 2021 by the authors. Licensee MDPI, Basel, Switzerland. This article is an open access article distributed under the terms and conditions of the Creative Commons Attribution (CC BY) license (https:/ / creativecommons.org/licenses/by/ $4.0 /)$.

\begin{abstract}
Education is an important driving force for sustainable social development. Emerging technologies such as extended reality (XR), including augmented reality (AR), virtual reality (VR) and mixed reality (MR), have been widely used. Recently, a large number of theoretical and empirical studies on the use of XR in the field of education for sustainable development have emerged. This paper uses bibliometric analysis to analyze the publication and citation trends of articles, prolific authors, institutions and countries, influential works, current topics, emerging trends, and knowledge structure to explore the overall productivity and XR research trends in the field of education for the period 1991-2021. Future development directions are also considered. On the basis of bibliometric analysis, this paper puts forward suggestions for the application of XR in the field of education for sustainable development.
\end{abstract}

Keywords: extended reality; education; bibliometric analysis; sustainable development

\section{Introduction}

The 2030 Agenda for Sustainable Development illustrates Goal 4 "ensure inclusive and equitable quality education and promote lifelong learning opportunities for all" [1] How might the problems of uneven educational resources, educational equity, and citizens' rights to education and the deep-seated social problems in resource-poor settings be addressed? The integration of modern technology and education, such as the popularization of extended reality (XR) in education, could help to solve these problems, thus promoting the sustainable development of education.

Technology is influencing the shape of education. However, the in-depth sustainable development of education needs wider application of modern information technology. The development of science and technology encourages educators to constantly explore and apply new technologies, methods, and practices in teaching, so as to further develop the quality and efficiency of education. As the boundary between the virtual world and the real world is being blurred by technology, it offers exciting possibilities for future education. The famous reality-virtuality (RV) continuum has been proposed [2,3]. There are different forms of reality: "real environments (RE), augmented reality (AR), mixed reality (MR), augmented virtuality (AV), virtual reality (VR)" [2]. XR, which includes VR, AR, and MR [4-7], is a "superset which includes the entire spectrum", from "the complete real" to "the complete virtual" in the virtuality continuum" [8]. These emerging technologies are influencing the development of education.

This study uses bibliometric analysis via VOSviewer and CiteSpace to analyze XR prospects for application in education. Bibliometric analysis was first proposed by Pritchard and refers to "the application of mathematical and statistical methods to books and other media communication" [9]. Bibliometric methods that draw scientific literature network maps can supplement traditional structured literature reviews and help explore certain 
research fields more deeply and comprehensively. It can identify the most influential countries, institutions, authors, works, and research trends through the quantitative results of publications [10-12]. Compared to traditional reviews, bibliographic analysis offers a wider perspective in terms of analysis coverage and depth of literature review [13,14]. This study focuses on the following questions.

Q1. What are the publication and citation trends of XR in education?

Q2. Who are the leading authors, institutions, and countries with most publications on the topic of application XR in education?

Q3. Which journals and publications were the most cited on the application of XR in education?

Q4. What are the current trending topics in the application of XR in education, and what are the key insights brought by these topics?

\section{Definition and Application of Extended Reality}

\subsection{Virtual Reality}

$\mathrm{VR}$, in effect, "the entirely replacement of the real world with a digitally recreated one" [15]. Its "3I" features are immersion, interaction, and imagination [16]. "VR is a collection of diverse technology while it is more likely an immersion experience with the sense of presence in learning" [17]. It is simulated experience, which may simulate the real world or be completely different from the real world [7]. VR offers users an opportunity to immerse themselves in a virtual environment and completely isolate themselves from reality [7]. An understanding of the current state of the application of this technology is needed to develop its strength and make up for its shortcomings.

Surveys on VR and its applications in education have been done [18]. VR has been applied to the field of education, and shows great potential to promote teaching reform and innovation, in areas such as preschool education [19], physics experimental teaching [20], geographical experiment [21], medical training [22], and art and design [23].

\subsection{Augmented Reality}

$\mathrm{AR}$ is "a variation on virtual environments that combines virtual and real" [24]. AR is a technology that integrates virtual information into the real world within an interactive experience [7]. In recent years, AR technology has attracted much attention in mathematics and science, because it can create a personalized learning environment and enhance students' activity [25]. It can provide real-time interaction [26], concretize information, and create a permanent learning environment [27]. Other AR benefits include creating experiences that people cannot access in real life [28]. The application of AR in science education can help students understand abstract concepts by realizing the three-dimensional representation of images, invisible and difficult to visualize events [29]. It can provide realistic topics to help students learn foreign languages [30] and offer natural experience in the learning environment [31].

\subsection{Mixed Reality}

As proposed in the reality-virtuality (RV) continuum [2,3], MR encompasses "both $\mathrm{AR}$ and $\mathrm{AV}$, the MR portion of the RV continuum covers essentially the entire breadth of the spectrum, but also excludes the end points" [32]. MR combines aspects of VR and AR to overlay virtual objects into the real world [7]. This helps professionals and educators in various fields training learners in professional skills, training them in a reallike environment. MR technology plays an important role in professional skill training in special fields such as medical [33,34], industrial [35], humanitarian security [36], and the military [37].

\subsection{Application of Extended Reality in Education}

$\mathrm{XR}$ is "all real-and-virtual combined environments and human-machine interactions generated by computer technology and wearables" [38]. It combines wearable devices 
with computation applications which brings the audience a blend of real and virtual, human-computer interaction environment.

$\mathrm{XR}$ allows learners to more actively control their learning strategies which increases teacher-student interaction and connectivity [39]. Some researchers characterize the application of XR technology in education into four ways: observational learning, operational learning, social learning, and academic research [17]. Some hold that XR educational application scenarios relate to: (1) smart education product design; (2) implementation of game-based learning; (3) construction of smart learning environment; (4) design education; (5) special education [40]. Some studies have explored the effectiveness of technology application in education, such as biological experiments [41], and education related to art [42], language [43], music [44], healthcare [45], physical [46,47], and blended education [48].

\section{Data and Methods}

This paper explores research articles on XR application in education collected via the Web of Science (WoS) database for the period 1991-2021, inclusive. Data were retrieved on August 16, 2021. Keywords were searched in the topic column. The search function was as follows. TS $=$ (virtual reality AND education) OR (augmented reality AND education) OR (mixed reality AND education) OR (extended reality AND education). Document type was limited to research papers written in English. The articles indexed in SCIE (2786)/SSCI (1772)/ESCI (1116)/ A-HCI (89) were chosen. A journal may be double-indexed. A total of 4729 works were obtained. The research roadmap is shown in Figure 1.

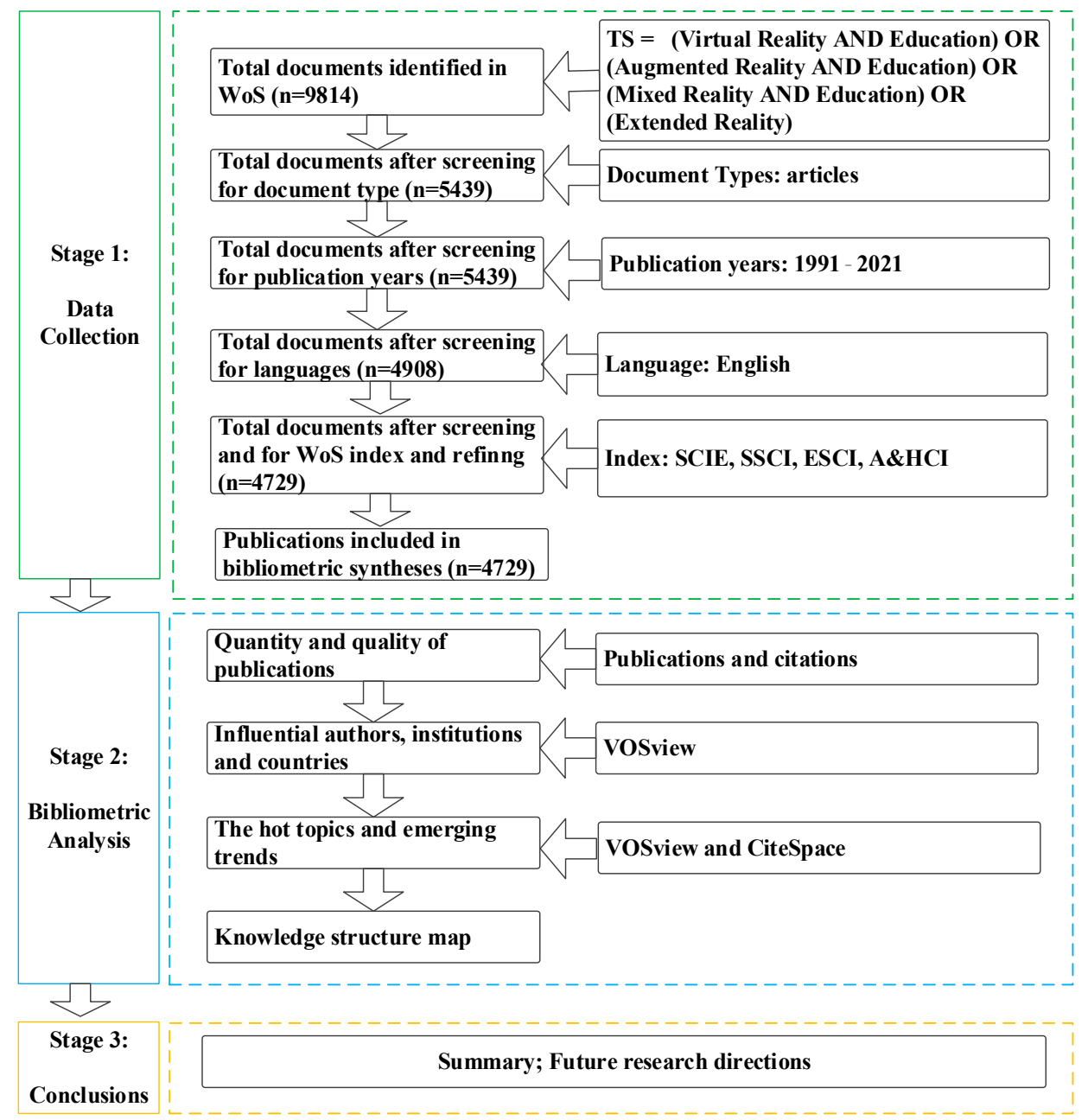

Figure 1. Research roadmap. 
Stage 1: Data collection. The keywords virtual reality, augmented reality, mixed reality, and extended reality were searched for combined with "education". Document types were limited to English language peer reviewed articles. The 4729 publications containing the topic of XR application in education indexed by SSCI, SCI, SCIE, and A\&HCI were identified.

Stage 2: Bibliometric analysis. The annual number of publications and citations was analyzed for the years 1991-2021. Influential author productivity, institutions, countries, and the most influential publications were visualized. Research trends were prospected by analyzing the more frequent keywords. A knowledge structure map was constructed using the bibliometric data.

Stage 3: Conclusions. The bibliometric findings were summarized, and future research and research limitations were envisioned.

\section{Results}

\subsection{Publication and Citation Trends}

Paper publishing trends, as measured by numbers, may be a measure of academic activity on a research topic and attention paid to a field [14]. Citation frequency is an important academic measure of publication quality. Figure 2 shows the number of publications and citations of papers related XR in education over time.

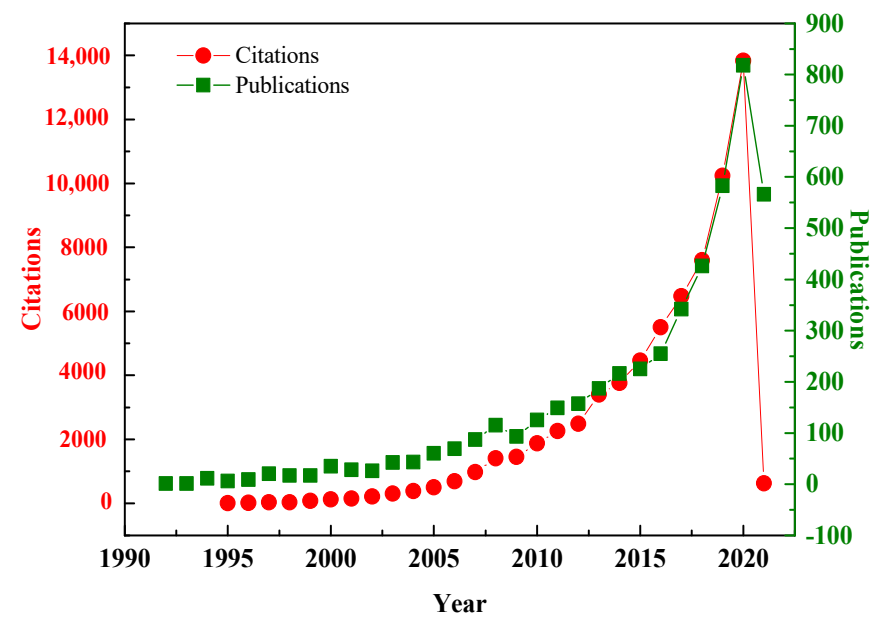

Figure 2. XR education citations and annual publications for 1991-2021.

There were 4729 total publications with 77,886 citations; 64,890 were without selfcitations; 44,872 citing articles and, 41,827 without self-citations. This indicates that scholars' research on the application of XR in the field of education started earlier and is becoming more and more mature. The annual count of documents and citations increased yearly. XR application in education was $12.33 \%$ in 2019. In 2020, 818 publications constituted $17.30 \%$. In 2021, 566 publications constituted 11.97\%. Based on the trends in August 2021, it was expected that the number of papers in 2021 would exceed that of 2020. In 2008, there were 115 papers constituting 2.43\% of all papers published. Except for 2009, when there were 93 papers, the annual number exceeded 100. The application of XR technology to education has attracted great attention in the last decade.

\subsection{Leading Authors, Institutions, Countries, and Regions}

\subsubsection{Leading Authors and Collaboration}

An analysis of an author's work and relationships suggests the connections among leading researchers and authors. Figure 3 shows the co-author collaboration network. 


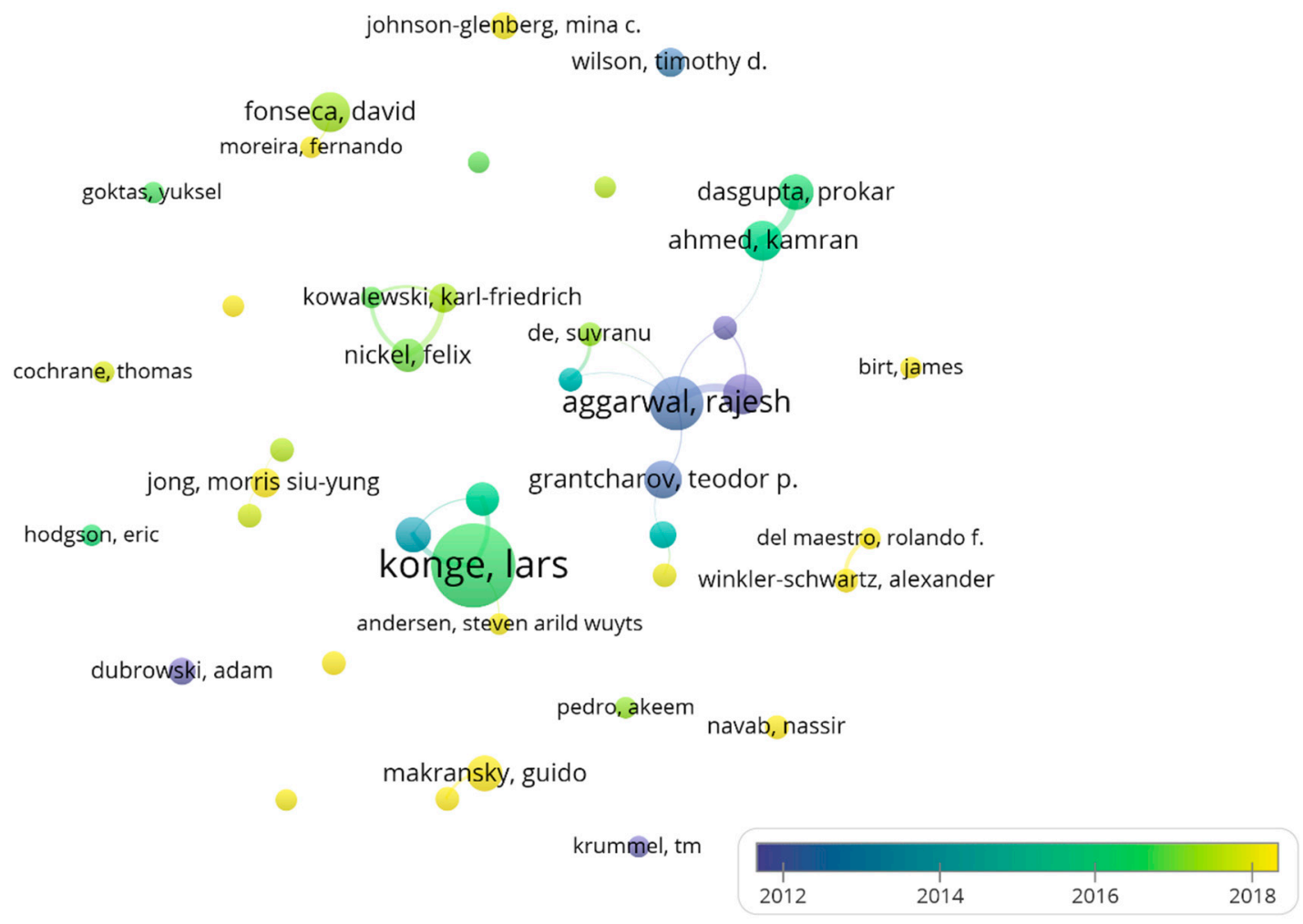

Figure 3. The overlay visualization of co-authorship networks.

Konge, Lars is the author with the most publications (42) on the topic of VR (Table S1 in Supplementary Materials). The "minimum number of publications of an author" was five. As the first author, Konge, Lars's paper named "Simulator training for endobronchial ultrasound: a randomised controlled trial" has been cited 56 times [49]. They found that VR simulation training has proved to be more effective than traditional apprenticeship training.

The second author with the largest number of articles is Aggarwal, Rajesh (Southend University Hospital), followed by Darzi, Ara (University of Wyoming), Ringsted, Charlotte (Aarhus University), and Ahmed, Kamran (King's College London) with more than 15 papers. Grantcharov, Teodor P. (Saint Michaels Hospital Toronto) is the author who has been cited most (978) and has the highest average citation (70). Several authors have published a large number of papers and the number of citations is unevenly distributed. Makransky, Guido as the first author has the largest number of articles $(n=8)$. They have published many papers on the topic on learning within immersive VR environments [50,51]. Among the top 10 leading authors, $40 \%(4 / 10)$ come from Denmark and 30\% (3/10) authors come from the UK.

\subsubsection{Leading Countries or Regions in Collaboration}

Country and regional cooperation networks were provided by VOSviewer, and the national and regional cooperation relations were identified, counted, and analyzed. The "minimum number of documents of a country" was set to six. Out of the 125 countries and regions, 66 countries and regions were included (Figure 4). Each node was an author who had made an important contribution to the field. These authors were divided into eight clusters. Node size refers to document numbers. For connection links, the thickness is the degree of international cooperation. The greater the number of texts from a country or region, the thicker the line and, the closer the cooperation relationship is between the two linked countries [14,52]. 

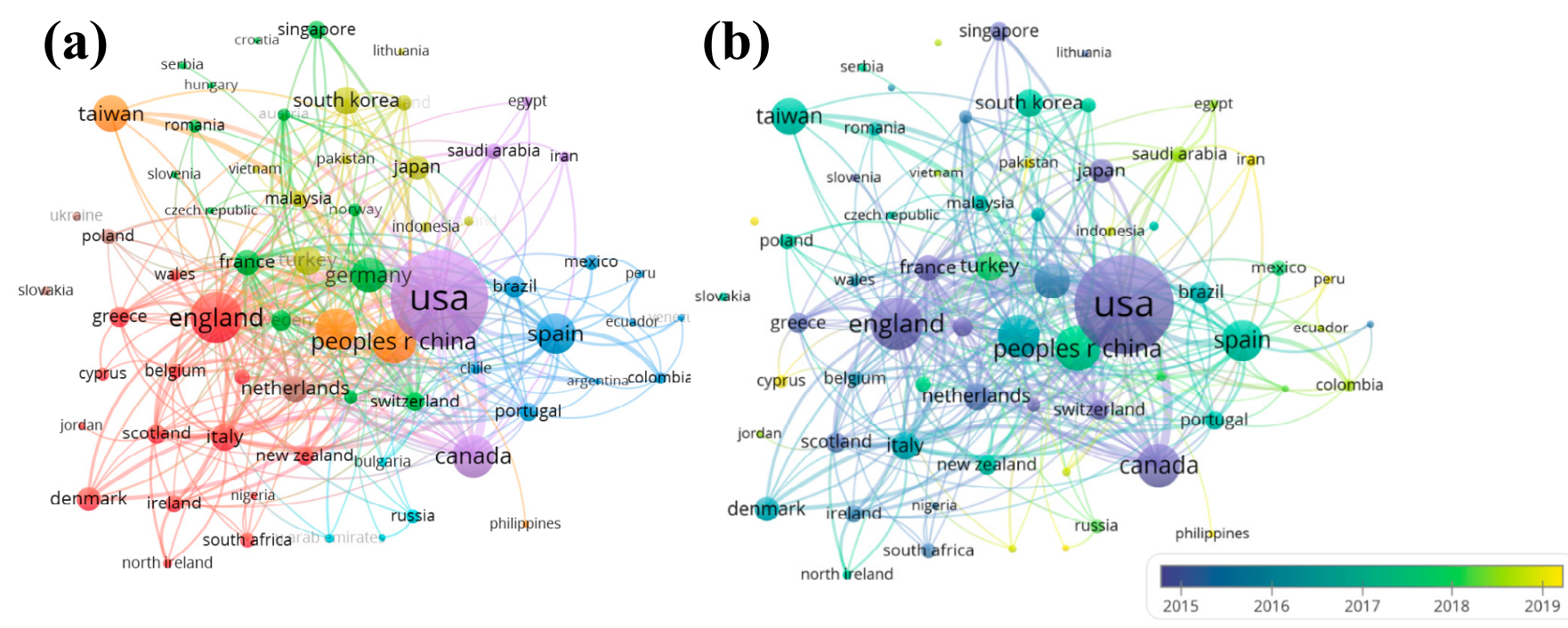

Figure 4. Country and region collaboration networks. (a) Collaboration network visualization map; (b) Collaboration overlay visualization map.

The USA and the UK were first and second in publications, with 1409 publications and 33,185 total citations and 419 publications and 8923 total citations, respectively (Figure 4a). The specific information is given in Table S2 in Supplementary Materials. The USA (purple) cooperates mostly with Canada, Saudi Arabia, Iran, and Egypt. The UK (red) cooperates mostly with Italy, Belgium, Greece, Ireland, Denmark, and New Zealand. Since 2015, more and more countries and regions have begun to attend to this topic, such as the People's Republic of China, Australia, Spain, Taiwan, Germany, Turkey, and Italy (Figure 4b).

\subsubsection{Leading Institutions and Collaborations}

Figure 5 illustrates the networks of institutional collaboration. Node size is directly proportional to publication numbers. The larger the node, the greater number of institution documents published. The connecting link indicates the degree of institutional academic cooperation. When the "minimum number of documents of an organization" was set to 15 , there were 79 of the 4257 organizations qualified. They were divided into nine clusters each represented by a different color (Figure $5 a$ ).

The University of Toronto has published the most documents exploring the use of VR in education (72) and has been cited the most (2278) (Table S3 in Supplementary Materials). This is followed by the University of Copenhagen, Stanford University, Harvard University, University of Illinois, and the University of Washington. It is worth mentioning that six out of ten institutions are from the USA. This suggests that US funders and educational institutions have long recognized the importance of XR technology application to education.

Figure $5 \mathrm{~b}$ shows that most of these universities began to investigate the application of XR in education before 2011, such as the Uniformed Services University of the Health Sciences, Emory University, University of Southern California, University of London, and University of Western Ontario. Recently, some universities have also begun to pay attention to XR education, for example, Radboud University Nijmegen, Harvard Medical School, National Cheng Kung University, Imperial College London, Western University, the Chinese University of Hong Kong, and the University of Auckland. 
(a)

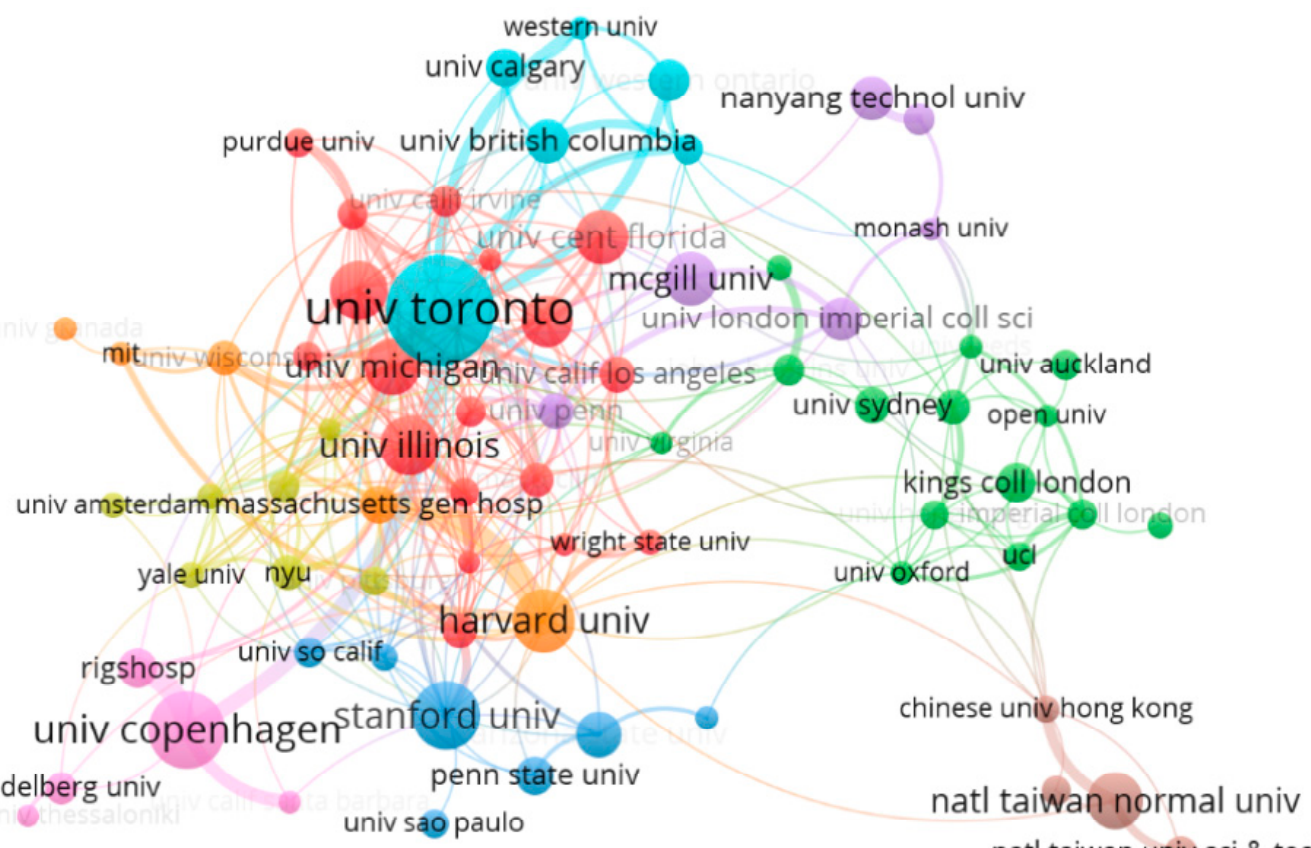

heidelberg univ

univ sao paulo natl taiwan normal univ

natl taiwan univ sci \& technol natl celet univ

(b)

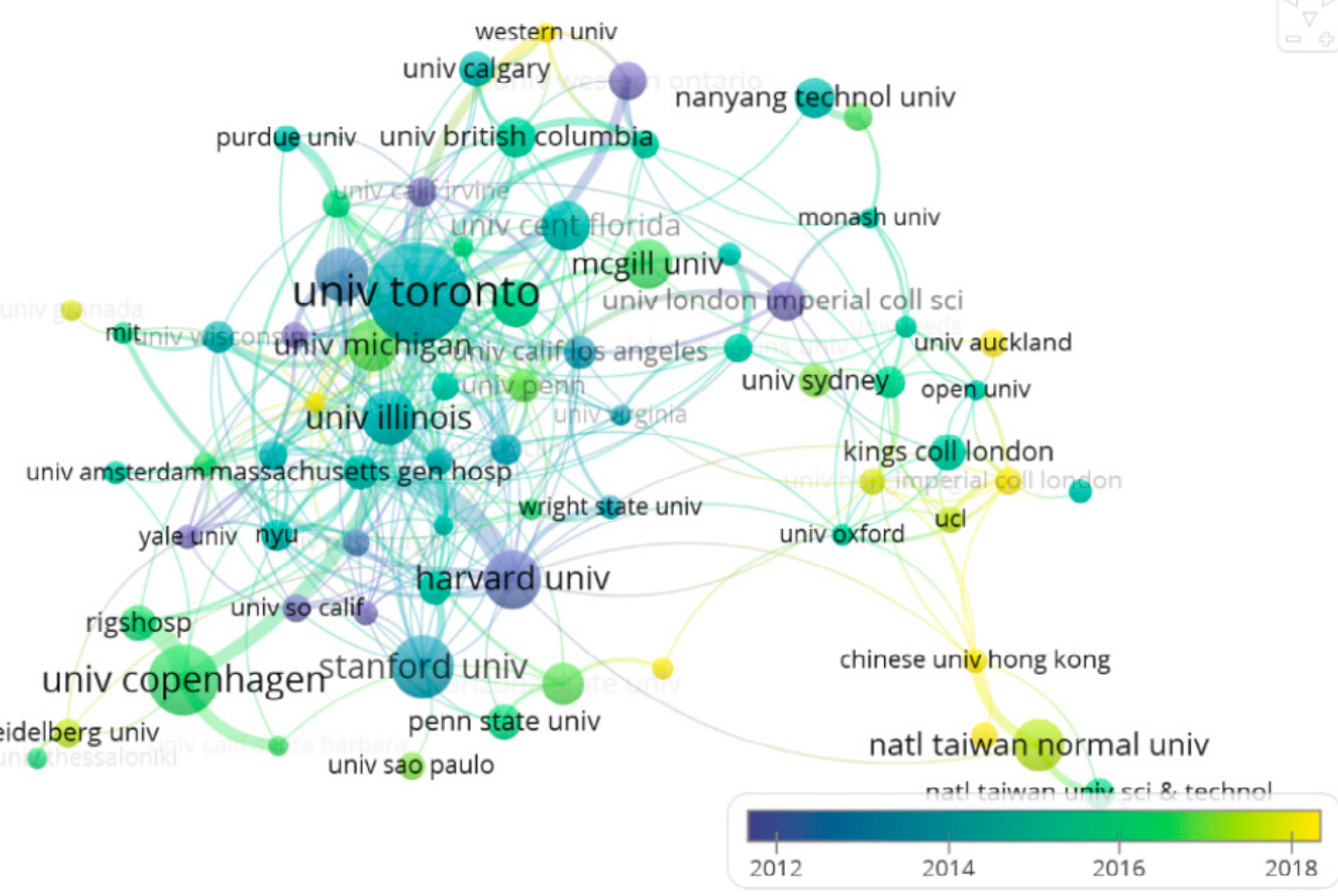

Figure 5. Institution collaboration network. (a) institution network visualization map; (b) Institution overlay visualization map.

\subsection{Influential Journals}

Source citation analysis generated a visualization network map of the most cited journals. With the "minimum number of documents of a source" set to 10, 74 out of 1726 journals were displayed (Figure 6a). The most cited journals are Computers and Education (9353 citations, 128 documents), Surgical Endoscopy and Other Interventional Techniques (2845 citations, 96 documents), Medical Teacher (2169 citations, 15 documents), American Journal of Surgery (2059 citations, 29 documents), and Anatomical Sciences Education (1867 citations, 61 documents). Four of the top five journals are medical. XR applications in medical education are more mature than those of other disciplines. Most 
early researchers and practitioners applied XR to the theory and practice of medical training. XR gradually extended to other disciplines.

Co-citation analysis of the cited sources was also conducted by VOSviewer. When the minimum number of citations of a source was set to 184,100 of the 50,800 sources appeared, as shown in Figure 6b. The most cited journals are Computers and Education (4635 co-citations), Surgical Endoscopy (2774 co-citations), Annals of Surgery (1711 cocitations), American Journal of Surgery (1537 co-citations), and Computers in Human Behavior (1349 co-citations). The top five journals belong to two disciplines, computer science and medicine.

(a)

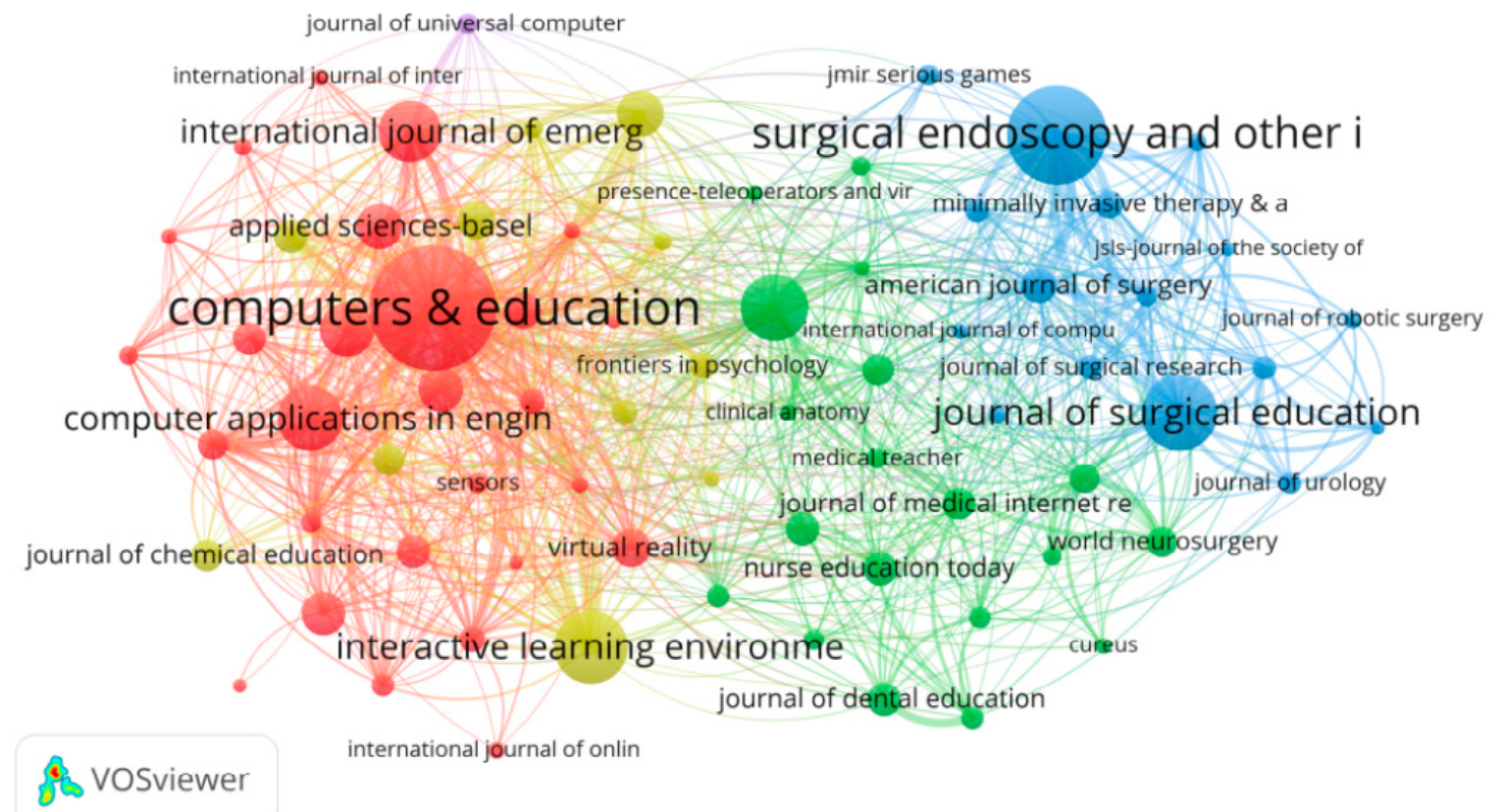

(b)

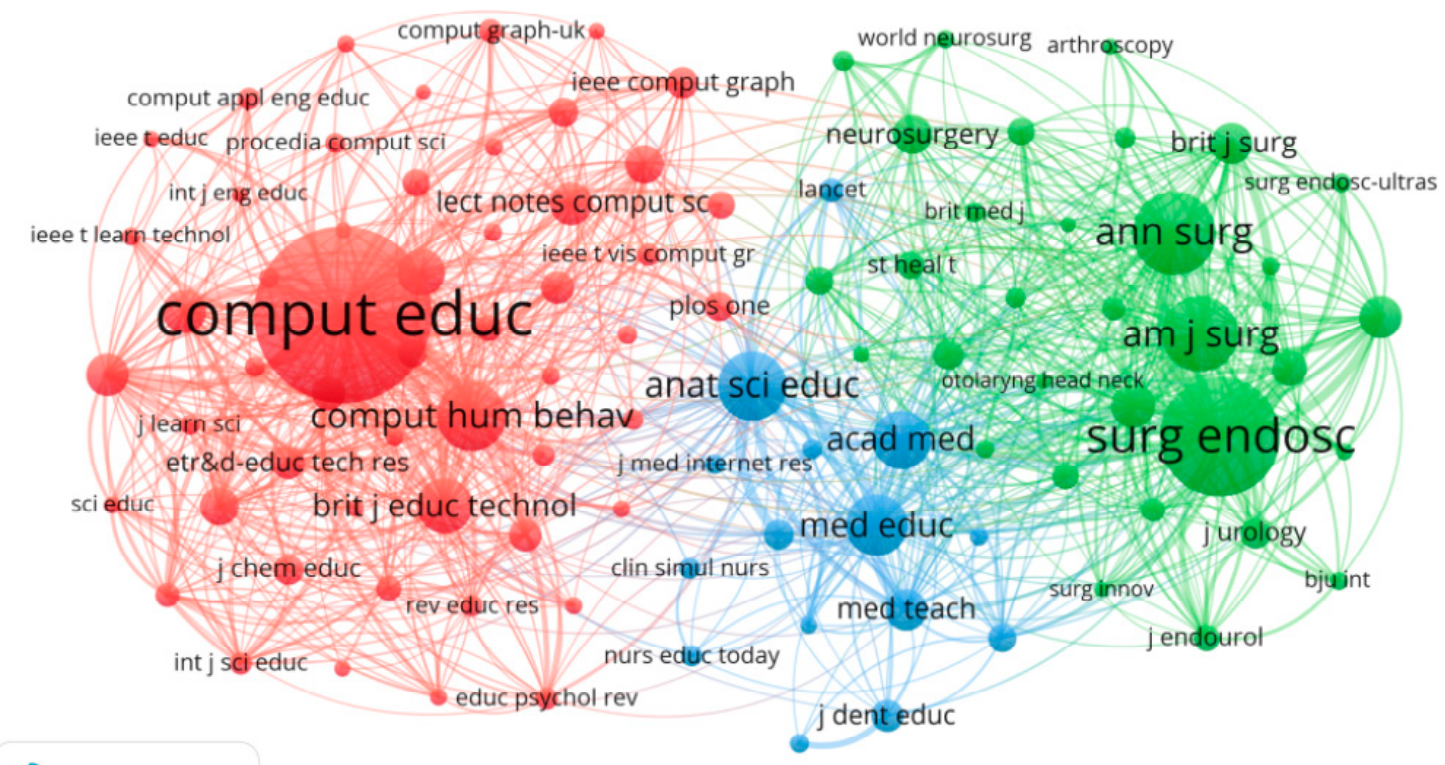

VOSviewer

Figure 6. Most cited journals. (a) The most cited journals based on citation analysis; (b) the most co-cited journals based on co-citation analysis. 


\subsection{Influential Works}

The number of citations may indicate the influence of that paper in a particular academic field $[14,53,54]$. Highly cited references appear in Table 1.

Table 1. Highly cited references.

\begin{tabular}{|c|c|c|c|c|c|c|c|}
\hline Rank & Journals & Titles & Year & Links & TS & Citations & Cluster \\
\hline 1 & $\begin{array}{l}\text { Annals of } \\
\text { Surgery }\end{array}$ & $\begin{array}{l}\text { Virtual reality training improves } \\
\text { operating room performance: results of } \\
\text { a randomized, double-blinded study } \\
\text { [55] }\end{array}$ & 2002 & 24 & 545 & 308 & 3 \\
\hline 2 & $\begin{array}{l}\text { Presence: } \\
\text { Teleoperators } \\
\text { and Virtual } \\
\text { Environments. }\end{array}$ & A survey of augmented reality [24] & 1997 & 34 & 942 & 280 & 1 \\
\hline 3 & $\begin{array}{l}\text { Computers \& } \\
\text { Education }\end{array}$ & $\begin{array}{c}\text { Current status, opportunities and } \\
\text { challenges of augmented reality in } \\
\text { education [29] }\end{array}$ & 2012 & 32 & 898 & 228 & 1 \\
\hline 4 & $\begin{array}{l}\text { British Journal of } \\
\text { Surgery }\end{array}$ & $\begin{array}{c}\text { Randomized clinical trial of virtual } \\
\text { reality simulation for laparoscopic } \\
\text { skills training [56] }\end{array}$ & 2010 & 20 & 412 & 182 & 3 \\
\hline 5 & $\begin{array}{c}\text { Educational } \\
\text { Research Review }\end{array}$ & $\begin{array}{l}\text { Advantages and challenges associated } \\
\text { with augmented reality for education: a } \\
\text { systematic review of the literature [57] }\end{array}$ & 2017 & 33 & 595 & 168 & 1 \\
\hline 6 & $\begin{array}{l}\text { Computers \& } \\
\text { Education }\end{array}$ & $\begin{array}{l}\text { Effectiveness of virtual reality-based } \\
\text { instruction on students' learning } \\
\text { outcomes in K-12 and higher education: } \\
\text { a meta-analysis [58] }\end{array}$ & 2014 & 35 & 250 & 157 & 2 \\
\hline 7 & $\begin{array}{c}\text { IEICE } \\
\text { Transactions on } \\
\text { Information } \\
\text { Systems }\end{array}$ & $\begin{array}{l}\text { A taxonomy of mixed reality visual } \\
\text { displays. IEICE transactions on } \\
\text { information and systems [59] }\end{array}$ & 1994 & 31 & 414 & 157 & 1 \\
\hline 8 & $\begin{array}{l}\text { J Sci Educ } \\
\text { Technol }\end{array}$ & $\begin{array}{l}\text { Affordances and limitations of } \\
\text { immersive participatory augmented } \\
\text { reality simulations for teaching and } \\
\text { learning [60] }\end{array}$ & 2009 & 30 & 685 & 151 & 1 \\
\hline 9 & $\begin{array}{l}\text { Educational } \\
\text { Technology \& } \\
\text { Society }\end{array}$ & $\begin{array}{l}\text { Augmented reality trends in education: } \\
\text { a systematic review of research and } \\
\text { applications [61] }\end{array}$ & 2014 & 32 & 588 & 143 & 1 \\
\hline 10 & $\begin{array}{l}\text { Computers \& } \\
\text { Education }\end{array}$ & $\begin{array}{l}\text { Impact of an augmented reality system } \\
\text { on students' motivation for a visual art } \\
\text { course [62] }\end{array}$ & 2013 & 32 & 591 & 132 & 1 \\
\hline
\end{tabular}

Six publications out of seven in cluster 1 focused on AR. Most of them are reviews of the research status, characteristics, opportunities, and challenges of applying AR technology to the field of education.

Only one of the top 10 references appears in cluster 2. A meta-analysis explored the effectiveness of VR in K-2 and higher education [58]. They proved that teaching based on VR effectively improves the learning effect.

Cluster 3 references concentrate on the research and discuss specific implementation strategies and cases of VR-based teaching $[55,56]$. These two papers are case studies of VR simulation applications in medical education. Results showed the application of VR training was very efficient in surgical education projects $[55,56]$. The innovative ideas put forward by so many excellent researchers have promoted XR applications in education. 


\subsection{Inspiration}

\subsubsection{Current Trending Topics}

Keywords summarize a paper's core content. Authors provide keyword retrieval, which can reflect a paper's themes, concepts, and methods [14]. VOSviewer was used to conduct a co-occurrence analysis by selecting keywords that appeared at least 42 times in publications. A total of 103 out of 12,678 keywords were extracted using this threshold. Node size and font are directly proportional to keyword frequency. The keyword "education" occurs the most (1563), followed by virtual reality (1304), augmented reality (819), simulation (642), performance (527), skills (333), surgery (326), technology (299), students (275), system (232), surgical education (216), reality (206), design (202), and medical education (194). The 103 keywords were divided into three clusters by different colors and representing the popular themes. Figure 7 shows the keywords occurrence networks.

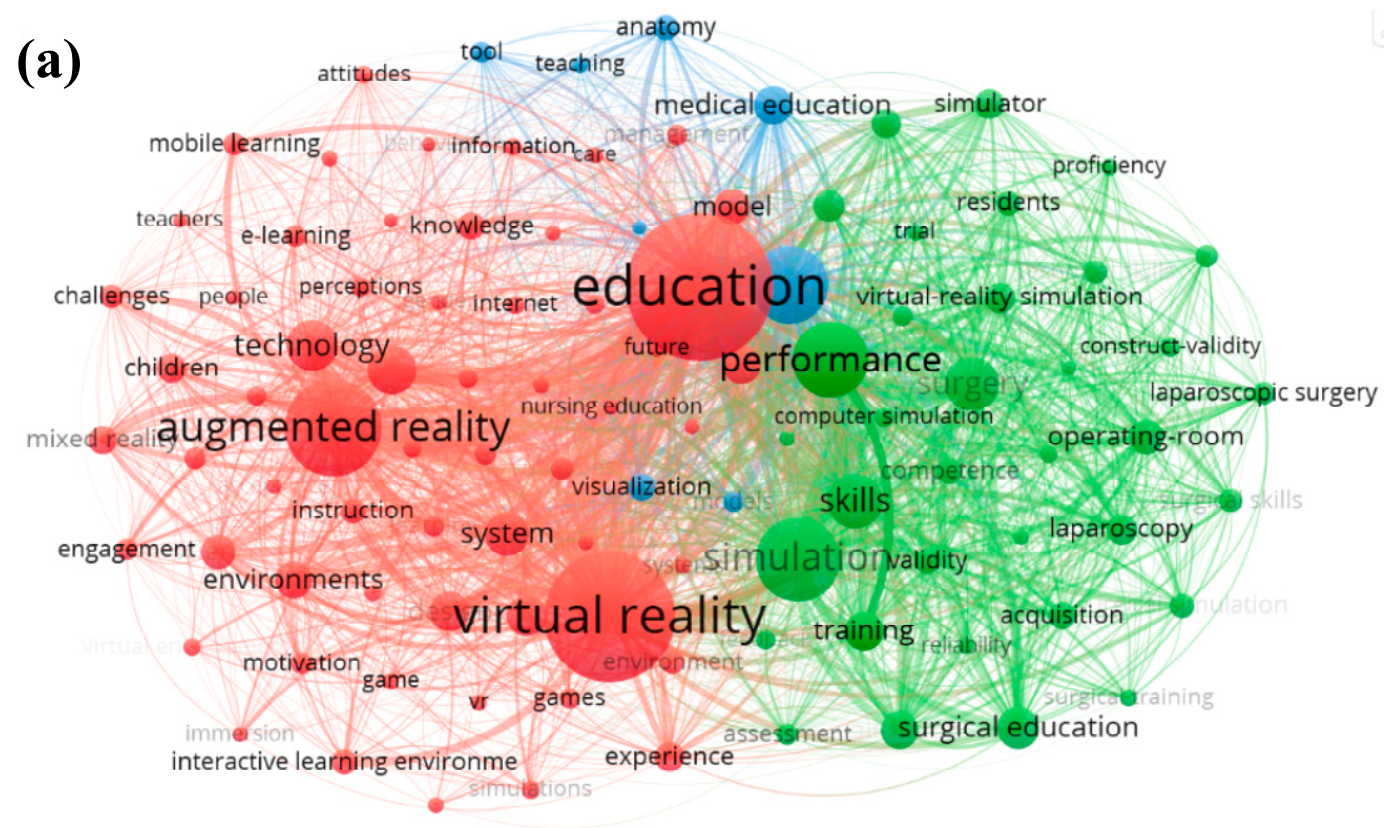

(b)

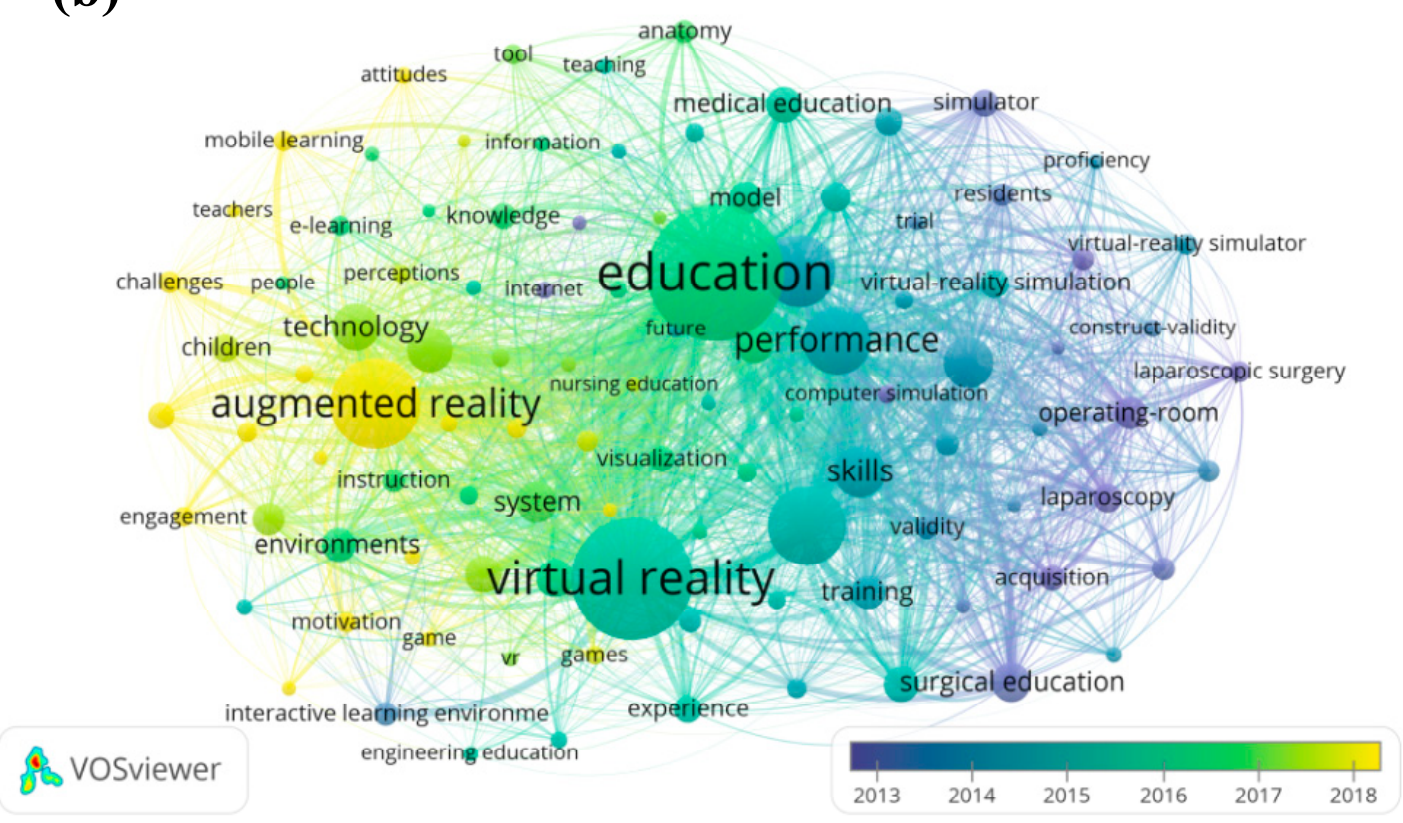

Figure 7. Co-occurrence keywords network: (a) occurrence-based visualization network; (b) the evolution of keywords based on the average publication year. 
In cluster 1, many prominent keywords were associated with the term "education". There were many prominent keywords, such as virtual reality, augmented reality, technology, students, system, reality, design, impact, and environment (Figure 7a; Table S4 in Supplementary Materials). In cluster 2, linked to the term "simulation" were keywords such as performance, skills, surgery, surgical education, validation, training, operating-room, medical-education, virtual-reality simulation, laparoscopy, and curriculum. This cluster highlights the characteristics and practical application of XR. It generates a simulation environment, so that users can immerse themselves in the environment.

In cluster 3, associated with the term "medical education" were keywords such as experience, mixed reality, visualization, anatomy, tool, learning, models, virtual environments, and teaching. The application of XR in medical education is of great significance and has attracted much attention. The combination of XR and surgery is an important research direction $[63,64]$.

As shown in Figure 7b, keywords occurring in 2019 according to the number of occurrences were ranked as follows: challenges (87), engagement (78), and higher education (79). Keywords occurring in 2018 were as follows: augmented reality (819), mixed reality (118), outcomes (84), mobile learning (80), motivation (79), framework (75), games (70), perceptions (65), meta-analysis (58), attitudes (57), acceptance (47), cognitive load (47), and immersion (46). Keywords occurred the earliest in 2012 were as follows: operating-room (158), laparoscopy (132), acquisition (113), technical skills (87), laparoscopic surgery (84), computer simulation (66), Internet (58), and multimedia (47). Keywords occurred in 2013 were surgical education (216), simulator (123), surgical simulation (96), residents (94), reliability (47), and laparoscopic skills (42). XR technology creates a rich and attractive learning experience for learners, promotes educational equity, and enables students to obtain high-quality education. This presents the opportunity to greatly promote XR usage in education for sustainable development.

\subsubsection{Emerging Trends}

Cluster analysis was conducted to detect the overall situation of this field from different angles in order to fully consider the influence of different documents on timeliness and reflect the research trends in academic fields for each period [65]. A keyword cluster analysis was conducted using CiteSpace to explore the emerging trends and frontiers of XR in education [66]. Figure 8 shows the keyword clusters of XR in the field of education research. The cluster visualization network generated by CiteSpace returned high values of modularity $\mathrm{Q}(n=0.7329>0.3)$ and the mean silhouette $(n=0.8243>0.5)$ larger than standard. The label of the cluster is based on the naming pattern calculated by Log-Likelihood Ratio (LLR). Specific information about the keywords clusters is shown in Table S5 in Supplementary Materials.

The label of cluster 0 was minimally invasive surgery. This cluster indicates that the advantages of XR for the medical industry are more apparent than ever before. Some important and advanced technologies were utilized in the surgical education, such as VR, computer simulation, VR simulator, training, simulator, skills laboratory, robotics, simulation, and surgical simulation. This cluster indicates that the application of XR in surgical education was regarded as the mainstream research frontier and direction.

Cluster 1 was labeled as augmented reality. The most cited article suggested that a medical practitioner should use information technologies to align medical practices [67]. This article proposed that VR and artificial intelligence can be integrated with the field of anesthesiology in the future, so as to perfectly integrate the technical nature of the discipline, clinical practice, and computer technology [67]. 


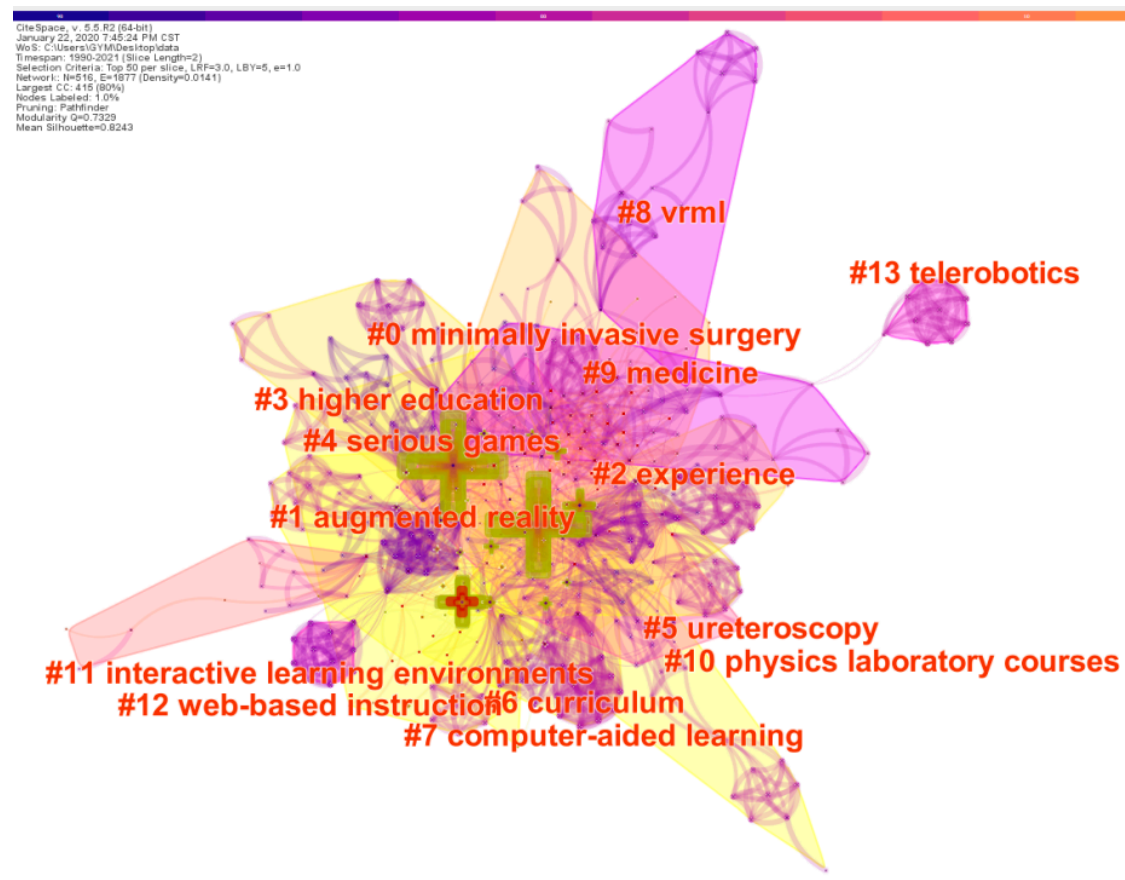

Figure 8. The clustering map of keywords.

The label of cluster 2 was experience. The referential document proposed that computer-based educational programs would prompt the development of anatomy [68]. Internship and operating experience are essential to the development of a qualified physician. AR technology was very popular in the education field. Publications and inventions in this promising research field are increasing.

Cluster 3 was labeled as higher education. Through scientific bibliometric analysis and content analysis, it can be found that the main institutions calling for the application of XR technology in education are colleges and universities. XR technology can be used to bring immersion education and experience to students, so that students can better take in knowledge, output knowledge, and apply knowledge to practice.

The label of cluster 4 was serious games. Serious games are a kind of video game that has been widely used in military, government, medicine, industry, education, scientific research, and training [69]. The reform of educational models increasingly advocates for the combination of education and games.

These 13 clusters can be divided into two research directions. One is the research focus on technology, such as cluster 1 (augmented reality), cluster 4 (serious games), cluster 8 (VRML), cluster 12 (web-based instruction), and cluster13 (telerobotics). Second is the research hotspots on education, such as cluster 0 (minimally invasive surgery), cluster 2 (experience), cluster 3 (higher education), cluster 5 (ureteroscopy), cluster 7 (computeraided learning), cluster 9 (medicine), cluster 10 (physics laboratory courses), and cluster 11 (interactive learning environments). Much research has focused on XR application in education, and many researchers or practitioners have focused on the application in surgery education, such as cluster 0 , cluster 5 , and cluster 9 .

Keyword citation burst is an important identifier of emerging research trends [70]. In order to better understand which research hotspots frequently appear and how long they lasted in each time period, this study used CiteSpace to conduct the keyword citation burst analysis (Figure 9). Before 2000, the most attended to topics in the XR field were medicine, computer, internet, multimedia, and endoscopy. This puts forward the possibility and prospect of XR application in education. 


\section{Top 25 Keywords with the Strongest Citation Bursts}

\begin{tabular}{|c|c|c|c|c|c|}
\hline Keywords & Year & Strength & Begin & End & $1990-2021$ \\
\hline medicine & 1990 & 4.512 & 1995 & 2002 & . \\
\hline computer & 1990 & 6.3559 & 1996 & 2007 & \\
\hline internet & 1990 & 9.8338 & 1997 & 2005 & 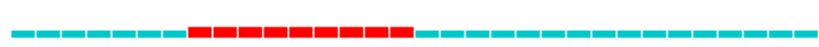 \\
\hline multimedia & 1990 & 6.9725 & 1997 & 2009 & 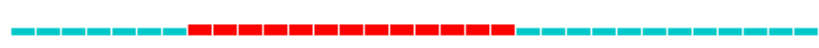 \\
\hline endoscopy & 1990 & 3.5012 & 1998 & 2007 & - \\
\hline teaching & 1990 & 4.7592 & 2000 & 2007 & 年 \\
\hline interactive learning environment & 1990 & 14.2381 & 2000 & 2015 & 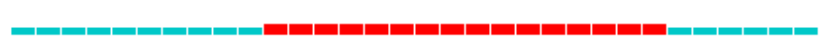 \\
\hline mist vr & 1990 & 10.319 & 2001 & 2007 & - \\
\hline computer simulation & 1990 & 16.4639 & 2001 & 2015 & \\
\hline surgical simulation & 1990 & 11.0965 & 2001 & 2017 & hen=m \\
\hline surgical education & 1990 & 8.4301 & 2001 & 2009 & - \\
\hline telemedicine & 1990 & 3.9422 & 2001 & 2009 & - \\
\hline trainer & 1990 & 3.7097 & 2002 & 2007 & 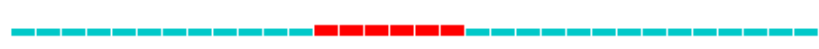 \\
\hline learning curve & 1990 & 15.2167 & 2002 & 2017 & 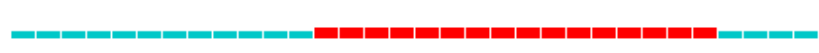 \\
\hline acquisition & 1990 & 20.1596 & 2002 & 2014 & 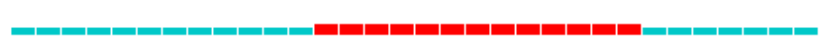 \\
\hline validity & 1990 & 7.3403 & 2002 & 2017 & - \\
\hline technical skill & 1990 & 19.326 & 2002 & 2015 & 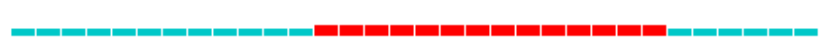 \\
\hline laparoscopy & 1990 & 22.2037 & 2002 & 2017 & 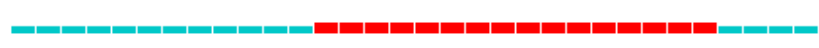 \\
\hline resident & 1990 & 14.8548 & 2002 & 2017 & 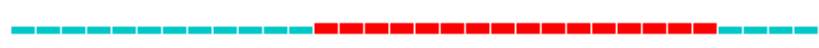 \\
\hline management & 1990 & 8.2871 & 2002 & 2013 & 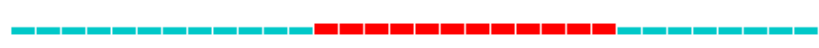 \\
\hline surgery & 1990 & 5.5658 & 2003 & 2010 & 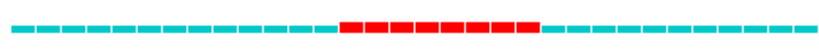 \\
\hline simulator & 1990 & 14.9154 & 2003 & 2013 & 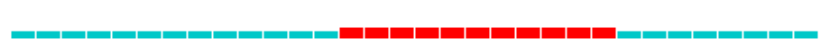 \\
\hline laparoscopic skill & 1990 & 10.4006 & 2004 & 2013 & 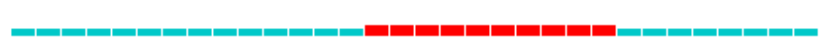 \\
\hline reliability & 1990 & 6.6431 & 2004 & 2015 & 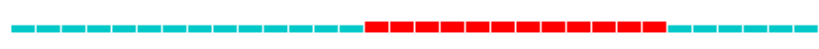 \\
\hline psychomotor skill & 1990 & 13.242 & 2004 & 2011 & 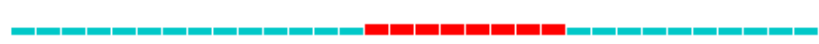 \\
\hline
\end{tabular}

Figure 9. Top 25 keywords with the strongest citation bursts.

After 2000, this popularity moved into practice from the prospect stage. More attention has been paid to these topics, such as teaching, interactive learning environment, Minimally Invasive Surgical Trainer in Virtual Reality (MIST-VR), computer simulation, surgical simulation, surgical education, telemedicine, trainer, learning curve, acquisition, validity, technical skill, laparoscopy, resident, management, surgery, simulator, laparoscopic skill, reliability, and psychomotor skills. Some keywords can also be seen frequently in keyword cluster analysis. They are high-frequency words for research. Many researchers have focused on the application of XR technology to the field of surgical education.

Smart learning environments improve learner-interactive learning. Learners are at the center of personalized learning support provided for effective learning through the support of various new technologies, tools, resources, and activities. Using XR interactive training can make knowledge retention longer and promote knowledge transfer [71]. The smart interactive learning environment supported by XR technology should be the development trend in the next stage, providing learners with machine-based collaborative learning, seamless connection between virtual and reality, and distance immersion education.

\subsubsection{Education for Sustainable Development}

In addition to the above research directions, some keywords reflect issues of researchers in 2021, such as smart learning environments, COVID-19, deep learning, preservice teachers, molecular modeling, behavioral intention, achievements, laboratory instruc- 
tion, $\mathrm{XR}, \mathrm{AR}, \mathrm{VR}$, and machine learning. In particular, keywords such as sustainability and sustainable development have been popular topics since 2019. With the concept of smart city, smart education based on XR technology for sustainable development will be paid more and more attention.

The application of XR helps build a sustainable learning environment. Education for sustainable development can encourage individuals, communities, organizations, and countries to contribute to sustainable development, such as making correct decisions and choices. Sustainable development education can change people's mentality and encourage them to cooperate in order to build a safer, healthy, and prosperous country [72]. Sustainable development education cultivates people's innovative thinking, critical thinking, and speculative thinking, promotes people's continuous exploration and discovery, and boosts the development of new technologies, new theories, new methods, and new tools [72].

Using pedagogical techniques such as XR technology in education can "promote active and participatory learning and the development of key dispositions and skills" [72]. Compared with the traditional classroom face-to-face teaching method, XR technology has many advantages in education, such as not being limited by time and space and providing an immersion experience. It can expand the multi-dimensional space of learning and improve student interest in seeking knowledge. With the help of XR technology, constructing the most important element of a "learning environment" can enable learners to experience the scene of the target knowledge application environment across time and space, and truly realize learner-centered teaching.

XR technology provides a driving force for the sustainable development of education. It promotes the update of international education model, from simple physical or virtual teaching to virtual real integration and seamless connection between online and offline. The interaction between teachers and students across time, space, scene, and mode will be promoted. XR in education supports the sharing of educational resources and services among countries and regions, and vigorously promotes educational equity.

\subsection{Knowledge Structure for XR in Education}

In order to show clearly the knowledge evolution of applying XR in education, an integrated knowledge structure map was built (Figure 10). Following the method used in a prior study [73], the knowledge structure map was composed of the knowledge base, knowledge domain, and knowledge evolution.

The knowledge base was constructed using co-occurrence keywords, divided into three clusters. High-frequency keywords are popular topics in academic research, such as education, virtual reality, augmented reality, technology, students, system, reality, design, impact, environments, and models. These research topics can be classified four ways, such as theoretical research, environmental construction, technical support, and practical research.

In the early stages, there was much theoretical discussion concerning XR. Recently, more and more attention has been paid to the practical application of XR in experiments and teaching platforms. In order to understand the major research content, the knowledge domain was built based on cluster analysis.

The theoretical research focused on teaching design using XR technology, such as higher education (cluster 3), curricula (cluster 6), and physics laboratory courses (cluster 10). A good virtual teaching and learning environment is the basis to ensure learners' virtual experience. Researchers have been exploring how to build a good environment combining the virtual and the real, such as using serious games (cluster 4) in teaching and interactive learning environments (cluster 11). With the continuous development and progress of $\mathrm{XR}$ and the reduction of hardware equipment cost, it will be more widely used in education with strong technical advantages and potential. 


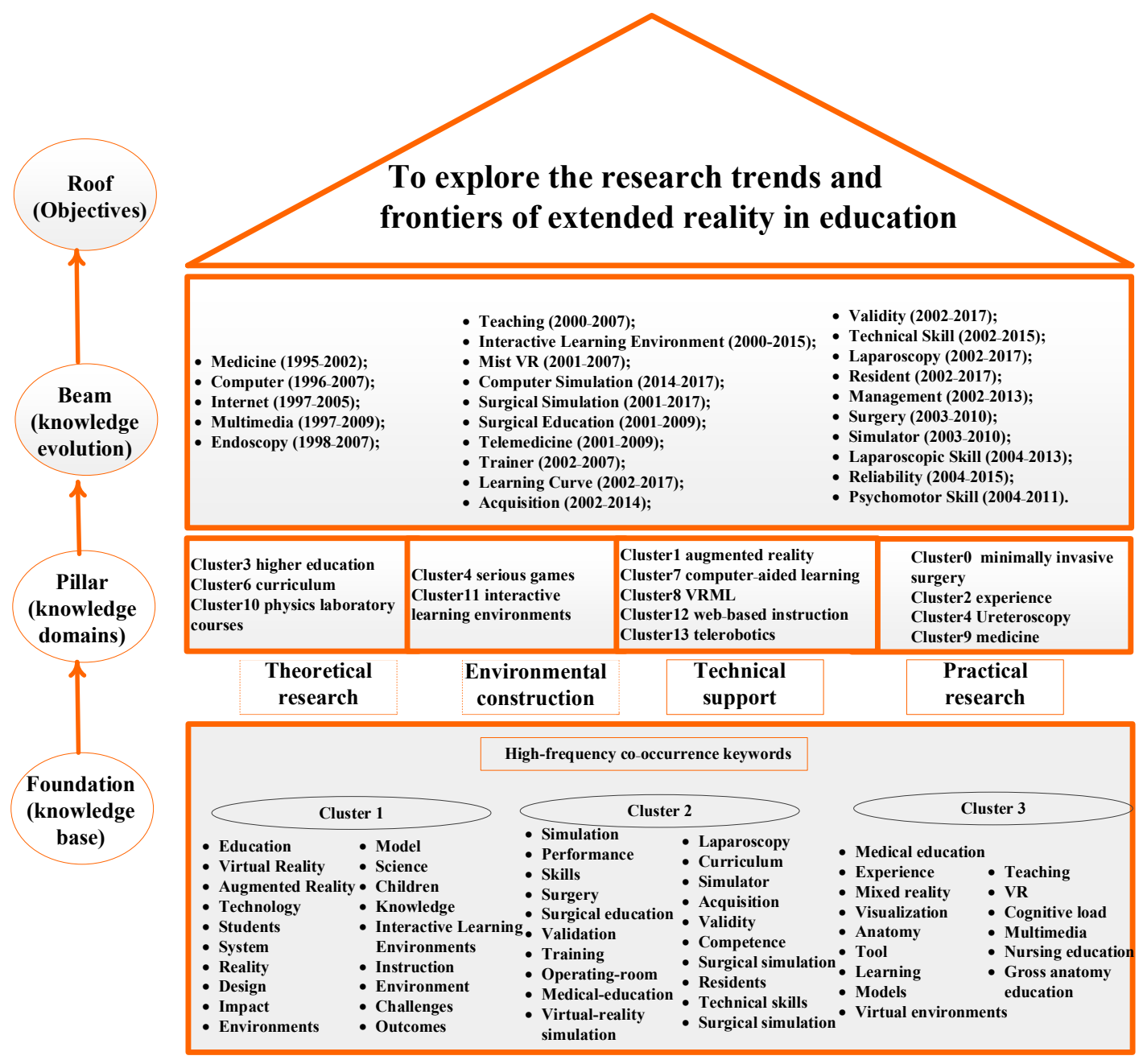

Figure 10. Knowledge structure map.

As for technical support, research focuses on these topics, such as augmented reality (cluster 1), computer-aided learning (cluster 7), virtual reality modeling language (VRML) (cluster 8), web-based instruction (cluster 12), and telerobotics (cluster 13). The application of XR in education has been involved in many aspects, such as minimally invasive surgery (cluster 0), experience (cluster 2), ureteroscopy (cluster 4), and medicine (cluster 9).

The application of XR technology to education presents a new challenge for educational reform. In addition to the support of the above factors, education based on XR technology mainly depends on the participation of teachers and students. The knowledge evolution has been reflected in the citation burst analysis. In the early stages of the research field, most attention focused on medicine (1995-2002), computer (1996-2007), Internet (1997-2005), multimedia (1997-2009), and endoscopy (1998-2007). Since 2000, the citation burst analysis shows that these topics have attracted much attention, namely teaching (2000-2007), interactive learning environment (2000-2015), mist VR (2001-2007), and computer simulation (2014-2017). On this topic, the focus of research has gradually shifted from theory to practical research.

Applying XR technology to the field of education is a cutting-edge topic. It is a rapidly developing field. Therefore, the research foundation, research field, and research evolution will develop and change dynamically. The focus of education has shifted from imparting simple technology to cultivating students' high problem-solving ability and creativity. Modern technologies such as XR can create more lifelong learning opportunities for formal, non-formal, and informal learning, thus promoting sustainable development [1]. This will 
help educators to have quality education and improve peoples' lives and facilitate the achievement of sustainable development goals.

\section{Discussion}

Over the past three decades, the number of publications and citations has gradually increased. XR is a sunrise research field not bounded by any specific discipline. XR research presents a promising interdisciplinary research trend. XR technology is becoming a force for teaching change and educational reform that should not underestimated. Its support for personalized learning, the reform of teaching mode, and the virtualization of the learning environment are the key nodes to bring about the reform of students' learning methods.

This study found that the leading researchers, institutions, countries, and journals in this field are all from developed countries, as are their research collaborators and institutions. Researchers in developed (high-income) countries tend to invest more in developing technologies and applied products, while researchers in low-income economies use technologies invented in advanced countries [74]. XR applications are expected to gain traction in developing countries. The top 10 leading institutions with the most publications were all universities. XR is mainly used in university classrooms, while XR is also needed in primary and secondary school classrooms, such as mathematics, physics, chemistry, biology, to make the acquisition of knowledge more immersive and improve learning enthusiasm. This may be the direction of future research.

The top cited journals are in the disciplines of computer science, medicine, and education. The interdisciplinary nature of XR application in education is evident through content analysis. Most papers are authored by multiple authors. There is a growing tendency for international researchers to collaborate. Cooperation embodies specialization, financial support, and division of labor.

Research trends and directions analysis can provide a reference research perspective for future researchers and practitioners to better understand the academic theme of this topic. Popular topics in this field include education, augmented reality, simulation, performance, skills, surgery, technology, students, system, surgical education, reality, design, and medical education.

The emerging trends can be understood from two research directions. One is the research focus on technology, the second being education. Many researchers' research interests on XR technology mostly involve concepts, characteristics, technical principles, equipment, application status in different fields, existing problems, and future prospects. At present, XR has been preliminary integrated with the field of education, with its XR integration, deep interaction, and coexistence of different time and space objects. It shows obvious technical advantages in subject classroom teaching, STEAM education, educational games, remote guidance and online virtual classroom, intangible cultural heritage education, and skill training in specific fields, and has unlimited potential development and application space. Researchers not only need to deeply develop new technologies, but also actively invest in the application practice of new technologies, such as developing virtual teaching resources, building XR intelligent classrooms, building virtual online learning environments, etc. New technologies would be applied to bring innovative changes to education.

In recent years, researchers have successfully developed and updated the software and equipment to realize $\mathrm{XR}$, which has brought new opportunities and challenges to the construction of digital learning environment $[18,75]$. In the personalized learning of XR education, students generally have unique learning paths and learning methods, which need to be supported by learning environment and learning resources different from others. Therefore, the construction and application of relevant software equipment and supporting learning tools is the efficient way for $\mathrm{XR}$ to promote the transformation of students' learning style.

The demand for $\mathrm{XR}$ technology in the education industry is developing rapidly, but the technical service support has not kept up. There are still some problems to be solved in 
the application, especially the lack of XR educational courseware. Advanced technologies and facilities boost distance and classroom learning. A work-life balance would be more easily reached when XR facilities are applied in e-learning. Thus, the level of students' knowledge will be improved and they will more likely be interested in scientific technology knowledge and accept innovation more easily. Therefore, $\mathrm{XR}$ technology can promote the education for sustainable development [76].

\section{Conclusions}

This study explored XR overall research trends in the fields of education, collaboration among authors, institutions, and countries, influential journals and works, and popular topics in the application of XR to the field of education. This study will help scholars understand the publication and citation trends of papers, guide researchers to detect research trends, choose the appropriate journals, and pay attention to the most influential researchers in this field.

Bibliometric analysis found few papers in the literature on evaluating the effect of XR in education. What are the effects of XR application to teaching? What are the problems in application? The feedback, collection, and sorting of these problems can promote the improvement and reform of the application of XR applications in the field of education and promote education for sustainable development.

The application of XR is an emerging trend in the field of education. There will be more products of XR education. Educational technology is an indispensable component of sustainable development of education in the future.

Supplementary Materials: The following are available online at https:/ / www.mdpi.com/article/ 10.3390/su132413776/s1, Table S1: Leading authors based on document weight, Table S2: Leading countries/regions based on the number of publications, Table S3: Leading institutions based on the number of documents, Table S4: Top 20 keywords of VR in education, Table S5: Top terms in the top 13 clusters.

Author Contributions: Conceptualization, X.G.; methodology, X.G. and Y.G.; software, X.G. and Y.L.; validation, X.G., Y.G. and Y.L.; formal analysis, X.G.; resources, Y.L.; data curation, X.G.; writingoriginal draft preparation, X.G.; writing—review and editing, X.G. and Y.G.; visualization, Y.L.; supervision, X.G. and Y.G.; project administration, X.G., and Y.L.; funding acquisition, X.G. and Y.L. All authors have read and agreed to the published version of the manuscript.

Funding: This research was funded by the Shanghai Philosophy and Social Science Planning Education Youth Project, 2019, grant number B19005, and the Science and Education Joint Project of Hunan Self Science Foundation, 2020JJ7044.

Institutional Review Board Statement: Not applicable.

Informed Consent Statement: Not applicable.

Data Availability Statement: https://webofscience.com/WOS (accessed on 16 August 2021).

Acknowledgments: The authors thank the editor and reviewers for valuable suggestions and Stephen Laudig for revising efforts.

Conflicts of Interest: The authors declare no conflict of interest.

\section{References}

1. UNESCO. Education for Sustainable Development Goals: Learning Objectives; UNESCO: Paris, France, 2017.

2. Milgram, P.; Takemura, H.; Utsumi, A.; Kishino, F. Augmented reality: A class of displays on the reality-virtuality continuum. In Proceedings of the SPIE-The International Society for Optical Engineering, Boston, MA, USA, 31 October-4 November 1994; SPIE: Bellingham, WA, USA, 1994; pp. 282-292.

3. Milgram, P.; Colquhoun, J. A Taxonomy of Real and Virtual World Display Integration. In Mixed Reality: Merging Real and Virtual Words; Springer: Berlin/Heidelberg, Germany, 1999; pp. 5-30.

4. Carrasco, M.; Chen, P.H. Application of mixed reality for improving architectural design comprehension effectiveness. Autom. Constr. 2021, 126, 103677. [CrossRef] 
5. Weinel, J. Cyberdreams: Visualizing Music in Extended Reality. In Technology, Design and the Arts-Opportunities and Challenges; Springer Open: New York, NY, USA, 2020.

6. Gates-Stuart, E.; Hagan, A. STEAM-Empowering STEM with the Arts-Extended Reality-The Future of Immersive Learning. In Proceedings of the STEM 2020 on Demand, online, 27 April 2020.

7. Sugimoto, M. Extended Reality (XR:VR/AR/MR), 3D Printing, Holography, A.I. Radiomics, and Online VR Tele-Medicine for Precision Surgery. In Surgery and Operating Room Innovation; Springer: New York, NY, USA, 2021.

8. Evans, G.W.; English, K. The environment of poverty: Multiple stressor exposure, psychophysiological stress, and socioemotional adjustment. Child Dev. 2002, 73, 1238-1248. [CrossRef]

9. Pritchard, J. Statistical-bibliography or bibliometrics? J. Doc. 1969, 25, 348-349.

10. Service innovation implementation: A systematic review and research agenda. Serv. Ind. J. 2020, 40, 491-517. [CrossRef]

11. Bindra, S.; Parameswar, N.; Dhir, S. Strategic management: The evolution of the field. Strateg. Chang. 2019, 28, 469-478. [CrossRef]

12. Kammerer, K.; Göster, M.; Reichert, M.; Pryss, R. Ambalytics: A scalable and distributed system architecture concept for bibliometric network analyses. Futur. Internet 2021, 13, 203. [CrossRef]

13. Singh, S.; Dhir, S.; Das, V.M.; Sharma, A. Bibliometric overview of the technological forecasting and social change journal: Analysis from 1970 to 2018. Technol. Forecast. Soc. Change 2020, 154, 119963. [CrossRef]

14. Xue, J.; Reniers, G.; Li, J.; Yang, M.; van Gelder, P.H.A.J.M. A bibliometric and visualized overview for the evolution of process safety and environmental protection. Int. J. Environ. Res. Public Health 2021, 18, 5985. [CrossRef] [PubMed]

15. Kiryakova, G.; Angelova, N.; Yordanova, L. The potential of augmented reality to transform education into Smart education. TEM J. 2018, 7, 556-565. [CrossRef]

16. Burdea, G.C.; Coiffet, P. Virtual Reality Technology, 2nd ed.; Wiley: Hoboken, NJ, USA, 2003.

17. Liu, D.; Bhagat, K.K.; Yuan, G.; Chang, T.W.; Huang, R. The Potentials and Trends of Virtual Reality in Education. In Virtual, Augmented, and Mixed Realities in Education; Springer: New York, NY, USA, 2017.

18. Kamińska, D.; Sapiński, T.; Wiak, S.; Tikk, T.; Haamer, R.E.; Avots, E.; Helmi, A.; Ozcinar, C.; Anbarjafari, G. Virtual reality and its applications in education: Survey. Information 2019, 10, 318. [CrossRef]

19. Li, J. Research on the reform and innovation of preschool education informatization under the background of wireless communication and virtual reality. Wirel. Commun. Mob. Comput. 2021, 2021. [CrossRef]

20. Wang, W.; Wang, Y. Study on the Reform of the Physics Experimental Teaching in University Based on Virtual Reality Technology. In Proceedings of the 2020 IEEE 2nd International Conference on Computer Science and Educational Informatization (CSEI), Xinxiang, China, 12-14 June 2020; pp. 58-62.

21. Jiang, H.; Lin, X. Teaching reform of university's geographical experiment based on virtual reality technology. J. Sci. Teach. Coll. Univ. 2007, 4, 109-112.

22. Ruthenbeck, G.S.; Reynolds, K.J. Virtual reality for medical training: The state-of-the-art. J. Simul. 2015, 9, 16-26. [CrossRef]

23. Du, S. Discussion on the Reform of Teaching Mode of Art Design Specialty VR Virtual Reality Technology. In Proceedings of the International Conference on Application of Intelligent Systems in Multi-Modal Information Analytics; Springer: New York, NY, USA, 2021; pp. 596-603.

24. Zhu, Z.T.; He, B. Smart education: New frontier of educational informatization. E-Educ. Res. 2012, 12, 1-13.

25. Arici, F.; Yildirim, P.; Caliklar, Ş.; Yilmaz, R.M. Research trends in the use of augmented reality in science education: Content and bibliometric mapping analysis. Comput. Educ. 2019, 142, 103647. [CrossRef]

26. Malkawi, A.M.; Srinivasan, R.S. A new paradigm for Human-Building Interaction: The use of CFD and Augmented Reality. Autom. Constr. 2005, 14, 71-84. [CrossRef]

27. Walczak, K.; Wojciechowski, R.; Cellary, W. Dynamic interactive VR network services for education. In Proceedings of the Proceedings of the ACM symposium on Virtual reality software and technology, Limassol, Cyprus, 1-3 November 2006; pp. 277-286.

28. Wojciechowski, R.; Cellary, W. Evaluation of learners' attitude toward learning in ARIES augmented reality environments. Comput. Educ. 2013, 68, 570-585. [CrossRef]

29. Wu, H.K.; Lee, S.W.Y.; Chang, H.Y.; Liang, J.C. Current status, opportunities and challenges of augmented reality in education. Comput. Educ. 2013, 62, 41-49. [CrossRef]

30. Solak, E.; Erdem, G. A content analysis of virtual reality studies in foreign language education. Particip. Educ. Res. 2015, 2, 21-26. [CrossRef]

31. Sumadio, D.D.; Rambli, D.R.A. Preliminary evaluation on user acceptance of the augmented reality use for education. In Proceedings of the 2010 second international conference on computer engineering and applications, Bali Island, Indonesia, 19-21 March 2010; Volume 2, pp. 461-465.

32. Milgram, P. Mixed Reality. Mix. Real. 1999, 1, 1-26. [CrossRef]

33. Hayes, A.T.; Hughes, C.E. Using Human in The Loop Simulation in Virtual and Mixed Reality for Medical Training. In Proceedings of the NextMed / MMVR22: 22nd Medicine Meets Virtual Reality Conference, Los Angeles, CA, USA, 7-9 April 2016.

34. Burke, E.; Felle, P.; Crowley, C.; Jones, J.; Mangina, E.; Campbell, A.G. Augmented Reality EVAR Training in Mixed Reality Educational Space. In Proceedings of the Global Engineering Education Conference (EDUCON), Athens, Greece, $25-28$ April 2017.

35. Sautter, B.; Daling, L. Mixed reality supported learning for Industrial on-the-job Training. In Proceedings of the Conference on Learning Factories (CLF), Graz, Austria, 31 June-2 July 2021. 
36. Gonsalves, A. Applying Serious Gaming to Humanitarian Security: A Framework for Mixed-Reality Training; EISF: London, UK, 2015.

37. Cohen, J. Statistical Power Analysis for the Behavioural Science, 2nd ed.; IEA: London, UK, 1988; ISBN 0805802835.

38. Fast-Berglund, Å.; Gong, L.; Li, D. Testing and validating Extended Reality (xR) technologies in manufacturing. Procedia Manuf. 2018, 25, 31-38. [CrossRef]

39. Kuleto, V.; Stanescu, M.; Ranković, M.; Šević, N.P.; Păun, D.; Teodorescu, S. Extended reality in higher education, a responsible innovation approach for generation y and generation z. Sustainability 2021, 13, 11814. [CrossRef]

40. Chu, L.; Chen, W.; Yue, T.; Zheng, S. Rebuliding the experience: Extended reality (XR) technology and its education application outlook: Also discuss the trend of "education and new technology integration". J. Distance Educ. 2019, 37, 17-31.

41. Shim, K.-C.; Park, J.-S.; Kim, H.-S.; Kim, J.-H.; Park, Y.-C.; Ryu, H.-I. Application of virtual reality technology in biology education. J. Biol. Educ. 2003, 37, 71-74. [CrossRef]

42. Gao, M. XR-TECAN Teaching Model for Chinese Traditional Art Education. Sci. Insights Educ. Front. 2021, 10, 1365-1380. [CrossRef]

43. Panagiotidis, P. Augmented and Mixed Reality in Language Learning. Eur. J. Educ. 2021, 4, 28-44. [CrossRef]

44. Matthias, P.; Billinghurst, M.; Siang See, Z. This Land AR: An Australian Music and Sound XR Installation. In Proceedings of the 17th International Conference on Virtual-Reality Continuum and its Applications in Industry, Brisbane, Australia, 14-16 November 2019; pp. 1-2.

45. Aebersold, M. Facilitator Guide to Using the XR Innovation for Healthcare Videos: Caring for Patients Who Are Deaf or Hard of Hearing; University of Michigan: Ann Arbor, MI, USA, 2020.

46. West, S.T.; Shores, K.A. Does HOPSports promote youth physical activity in physical education classes? Phys. Educ. 2014, 71, $16-40$.

47. Glapa, A.; Grzesiak, J.; Laudanska-Krzeminska, I.; Chin, M.-K.; Edginton, C.R.; Mok, M.M.C.; Bronikowski, M. The impact of brain breaks classroom-based physical activities on attitudes toward physical activity in polish school children in third to fifth grade. Int. J. Environ. Res. Public Health 2018, 15, 368. [CrossRef]

48. Bauer, S.; Jowallah, R.; Gunter, G.; Futch, L. Broadening Blended Learning Via XR: A Case for Another Modality. In Proceedings of the E-Learn: World Conference on E-Learning in Corporate Government, Healthcare, and Higher Education; Association for the Advancement of Computing in Education (AACE), New Orleans, LA, USA, 4-7 November 2019; pp. 544-547.

49. Konge, L.; Clementsen, P.F.; Ringsted, C.; Minddal, V.; Larsen, K.R.; Annema, J.T. Simulator training for endobronchial ultrasound: A randomised controlled trial. Eur. Respir. J. 2015, 46, 1140-1149. [CrossRef] [PubMed]

50. Makransky, G.; Borre-Gude, S.; Mayer, R.E. Motivational and cognitive benefits of training in immersive virtual reality based on multiple assessments. J. Comput. Assist. Learn. 2019, 35, 691-707. [CrossRef]

51. Makransky, G.; Andreasen, N.K.; Baceviciute, S.; Mayer, R.E. Immersive virtual reality increases liking but not learning with a science simulation and generative learning strategies promote learning in immersive virtual reality. J. Educ. Psychol. 2021, 113, 719-735. [CrossRef]

52. Li, J.; Reniers, G.; Cozzani, V.; Khan, F. A bibliometric analysis of peer-reviewed publications on domino effects in the process industry. J. Loss Prev. Process Ind. 2016, 49, 103-110. [CrossRef]

53. Merigó, J.M.; Gil-Lafuente, A.M.; Yager, R.R. An overview of fuzzy research with bibliometric indicators. Appl. Soft Comput. J. 2015, 27, 420-433. [CrossRef]

54. Merigó, J.M.; Mas-Tur, A.; Roig-Tierno, N.; Ribeiro-Soriano, D. A bibliometric overview of the Journal of Business Research between 1973 and 2014. J. Bus. Res. 2015, 68, 2645-2653. [CrossRef]

55. Seymour, N.E.; Gallagher, A.G.; Roman, S.A.; O’Brien, M.K.; Bansal, V.K.; Andersen, D.K.; Satava, R.M. Virtual reality training improves operating room performance: Results of a randomized, double-blinded study. Ann. Surg. 2002, 236, 458-463. [CrossRef]

56. Grantcharov, T.P.; Kristiansen, V.B.; Bendix, J.; Bardram, L.; Rosenberg, J.; Funch-Jensen, P. Randomized clinical trial of virtual reality simulation for laparoscopic skills training. Br. J. Surg. 2004, 91, 146-150. [CrossRef]

57. Akçayır, M.; Akçayır, G. Advantages and challenges associated with augmented reality for education: A systematic review of the literature. Educ. Res. Rev. 2017, 20,1-11. [CrossRef]

58. Merchant, Z.; Goetz, E.T.; Cifuentes, L.; Keeney-Kennicutt, W.; Davis, T.J. Effectiveness of virtual reality-based instruction on students' learning outcomes in K-12 and higher education: A meta-analysis. Comput. Educ. 2014, 70, 29-40. [CrossRef]

59. Milgram, P.; Kishino, F. A Taxonomy of Mixed Reality Visual Displays. IEICE Trans. Inf. Syst. 1994, E77-D, 1321-1329.

60. Dunleavy, M.; Dede, C.; Mitchell, R. Affordances and limitations of immersive participatory augmented reality simulations for teaching and learning. J. Sci. Educ. Technol. 2009, 18, 7-22. [CrossRef]

61. Bacca, J.; Baldiris, S.; Fabregat, R.; Graf, S.; Kinshuk, G. Augmented reality trends in education: A systematic review of research and applications. Educ. Technol. Soc. 2014, 17, 133-149.

62. Serio, A.D.; Ibanez, M.B.; Kloos, C.D. Impact of an augmented reality system on students' motivation for a visual art course. Comput. Educ. 2013, 68, 586-596. [CrossRef]

63. Zweifach, S.M.; Triola, M.M. Extended reality in medical education: Driving adoption through provider-centered design. Digit. Biomarkers 2019, 3, 14-21. [CrossRef]

64. Barteit, S.; Lanfermann, L.; Bärnighausen, T.; Neuhann, F.; Beiersmann, C. Augmented, mixed, and virtual reality-based head-mounted devices for medical education: Systematic review. JMIR Serious Games 2021, 9, e29080. [CrossRef] 
65. Cohen, E.A.; David, K. The Codebreakers: The Comprehensive History of Secret Communication from Ancient Times to the Internet. Foreign Aff. 1997, 76, 129. [CrossRef]

66. Guo, Y.M.; Huang, Z.L.; Guo, J.; Guo, X.R.; Nkeli, M.J. A bibliometric analysis and visualization of blockchain. Futur. Gener. Comput. Syst. 2021, 116, 316-332. [CrossRef]

67. Schneider, E.C.; Eisenberg, J.M. Strategies and methods for aligning current and best medical practices. The role of information technologies. West. J. Med. 1998, 168, 311-318. [PubMed]

68. Aziz, M.A.; McKenzie, J.C. The dead can still teach the living: The status of cadaver-based anatomy in the age of electronic media. Perspect. Biol. Med. 1999, 42, 402-421. [CrossRef]

69. Susi, T.; Johannesson, M.; Backlund, P. Serious Games: An Overview; Institutionen för Kommunikation och Information: Lund, Sweden, 2007.

70. Kenekayoro, P. Author and keyword bursts as indicators for the identification of emerging or dying research trends. J. Scientometr. Res. 2020, 9, 120-126. [CrossRef]

71. Krajovi, M.; Gabajová, G.; Matys, M.; Grznár, P.; Dulina, U.; Kohár, R. 3D interactive learning environment as a tool for knowledge transfer and retention. Sustainability 2021, 13, 7916. [CrossRef]

72. Krishna, V.R.; Shashidhar, R.; Smitha, D. Sustainable development and thresholds of education: Education for sustainable development. Soc. Sci. Electron. Publ. 2016, 9, 35-42.

73. Shi, Y.; Liu, X. Research on the literature of green building based on the web of science: A scientometric analysis in citespace (2002-2018). Sustainability 2019, 11, 3716. [CrossRef]

74. Caselli, F.; Coleman, W.J. Cross-country technology diffusion: The case of computers. Am. Econ. Rev. 2001, 91, 328-335. [CrossRef]

75. Guo, X.R.; Li, X.; Guo, Y.M. Mapping Knowledge Domain Analysis in Smart Education Research. Sustainability 2021, $13,13234$. [CrossRef]

76. Bucea-Manea-Oni, R.; Bucea-Manea-Oni, R.; Simion, V.E.; Ilic, D.; Braicu, C.; Manea, N. Sustainability in higher education: The relationship between work-life balance and xr e-learning facilities. Sustainability 2020, 12, 5872. [CrossRef] 